\title{
PREVALENCE OF PRE DIABETES AND DIABETES MELLITUS AMONG AL-AZHAR UNIVERSITY MALE STUDENTS HOSTEL IN CAIRO EGYPT "CROSS SECTION STUDY"
}

By

\author{
Abd El-Wahab Mohamed Lotfy ${ }^{1}$, Mahmoud Hadad Hemeda ${ }^{1}$, Ahmed \\ Ezzat Abd El-Aziz Ali ${ }^{2}$, Ibrahim Metwally Bauomy ${ }^{3}$ and Mohammed \\ Gamil Hammed Shola ${ }^{1}$ \\ ${ }^{1}$ Department of Internal Medicine, Faculty of Medicine, Al-Azhar University \\ ${ }^{2}$ Department of community and Industrial Medicine, Faculty of Medicine, Al-Azhar \\ University \\ ${ }^{3}$ Department of Clinical Pathology, Faculty of Medicine, Al-Azhar University \\ Mobil: 01009709334, E-mail: gamilmohamed522@gamil.com
}

\begin{abstract}
Background: Diabetes mellitus (DM), is a group of metabolic disorders in which there are high blood sugar levels over a prolonged period. If left untreated, diabetes can cause many complications.

Objective: To identify the pre-diabetes and diabetes among Al-Azhar University male students Hostel.

Subject and Methods: A cross section study of 400 students from Al-Azhar University male students Hostel in Cairo Egypt during the period from first of October 2018 to the end of May 2019.

Results: Body mass index (BMI), overweight and obesity were statistically significantly associated with the risk of being diagnosed with DM among individuals without any other prior evidence of DM. The risk of DM diagnosis was increasingly larger for individuals in higher BMI categories than for individuals in lower BMI categories.
\end{abstract}

Conclusion: There was a positive correlation between HbA1c, body mass index (BMI) and Family history.

Keywords: Pre-diabetes, Diabetes mellitus, AL-Azhar University students, BMI.

\section{INTRODUCTION}

Diabetes mellitus (DM) is one five principal causes of death universally (Ding and Choi, 2015). A recognized basis to prevent this condition is to classify common modifiable risk factors that have an ultimate impact on the morbidity on top of developing community based programs for its control and prevention. Normally, by the time, an individual is diagnosed. They have a tendency to develop various complications, such as ischemic heart disease (a macroangiopathic procedure) or retinopathy (a microangiopathic process) (Okwechime and Roberson, 2015).

$\mathrm{DM}$ is of the commonest non communicable chronic disease with high worldwide prevalence in the current situation. Along with this, the pre-diabetic 
stage has also become prevalent. It is estimated that in 2025, 300 million people will be affected, and so it continues to be worldwide-growing epidemic (Hjelm et al., 2013). Globally, its prevalence has been found to be increasing, and by 2030 it can rise up to $<470$ million people suffering from it (Gossain and Aldasouqi 2010).

The decreasing age at onset of obesity has alarming public health implications (Cunningham et al., 2014). Obesityrelated metabolic abnormalities such as pre-diabetes and diabetes are becoming increasingly more common at progressively younger ages. The onset of $\mathrm{DM}$ is preceded by a long asymptomatic phase, represented by the presence of impaired fasting glucose (IFG) and/or impaired glucose tolerance (IGT), two distinct phenotypes of pre-diabetes with only partial overlap (Giannini and Caprio, 2013).

Although current guidelines recommend that the screening for altered glucose metabolism should start at 10 years of age (or at the onset of puberty, if puberty occurs at younger age). Scattered data suggest that pre-diabetic conditions, such as impaired fasting glucose (IFG) and impaired glucose tolerance (IGT), are emerging among obese youths at younger ages (Morrison et al., 2012).

The present work aimed to estimate the prevalence of pre-diabetics and diabetics as well as the risk factors in male students Hostel of Al-Azhar University.

\section{SUBJECTS AND METHODS}

A cross section study was conducted to identify new cases of pre-diabetics or diabetics, and to identify the risk factor of these cases among Al-Azhar University male students Hostel in Cairo, Egypt from the first of October 2018 to the end of May 2019.

The sample (400) was chosen by a stratified random technique from all students of the Hostel of Al-Azhar University in Nasr city, Cairo, Egypt.

All students were subjective to the following:

1. Complete history taking (name, age, sex, smoker, personal history, family history, and past history).

2. Full clinical examination.

3. BMI was calculated as weight in kilograms divided by height in meters squared $\left(\mathrm{kg} / \mathrm{m}^{2}\right)$ Normally, BMI > 25, overweight (25>BMI>30), and obese (BMI <30) groups were composed based on widely used cutoff values for assessing obesity (Lean et al., 2018).

4. Laboratory investigation in clouded, random blood sugar, fasting blood sugar, post prandial blood sugar and HbA1c.

\section{Blood sampling:}

Fasting blood sample wear collected after at least 8 hours from last meal, Post prandial blood sample was collected 2 hours after ingestion of $75 \mathrm{~g}$ glucose, and HbA1c blood sample was collected with post prandial blood sample.

The sample was collected in tubes without additional anticoagulant and allowed to stand at room temperature for 30 to 60 minutes, and then the sample was centrifuged to obtain serum which was stored at 20 until assayed. 
Approval was being obtained from the scientific ethical review committee. An informed verbal consent was obtained from every student involved in the study.

\section{Statistical analysis:}

Analysis of data was performed with a personal computer using SPSS Prism.
Statistical presentation and analysis of the present study was conducted, using the mean, standard deviation, Pearson correlation coefficient test by SPSS V.22.

Linear Correlation coefficient was used for detection of correlation between two quantitative variables in one group. $\mathrm{P}$ value $>0.05$ was considered significant.

\section{RESULTS}

This was a cross sectional open study of 400 students in Hostel of Al-Azhar University in Cairo. Their ages were between 18 and 24 years with a mean of 21 years all of them wear means. The mean value of age of studied sample was $20.74 \pm 1.28$, mean values of HA1C was $5.83 \pm 0.37$, the mean value of BMI was $23.22 \pm 2.34$. The mean value of fasting blood glucose and PP.BL sugar was $114 \pm 15.14$ and $171 \pm 26.39$ respectively. The mean value of Systolic blood pressure, diastolic blood pressure, RBCs, and HR was 115.3 $\pm 11.8976 .84 \pm 8.36$, $112.7 \pm 46.18$ and $84.05 \pm 6.16$ respectively. $31.5 \%$ of the studied sample having smoking history and $27.75 \%$ having a family history of diabetes (Table 1).

Table(1): Demographic and laboratory data of the studied sample

\begin{tabular}{|l|c|}
\hline Parameter & Mean \pm SD \\
\hline Age & $20.74 \pm 1.28$ \\
\hline glycated hemoglobin (HbAIC) & $5.83 \pm 0.37$ \\
\hline Body mass index (BMI) & $23.22 \pm 2.34$ \\
\hline Fasting blood glucose & $114 \pm 15.14$ \\
\hline Post pradinal blood Sugar & $171 \pm 26.39$ \\
\hline Systole & $115.3 \pm 11.89$ \\
\hline Diastole & $76.84 \pm 8.36$ \\
\hline Random blood sugar (RBs) & $112.7 \pm 46.18$ \\
\hline Heart rate (HR) & $84.05 \pm 6.16$ \\
\hline Smoking history & $126(31.5 \%)$ \\
\hline Family history & $111(27.75 \%)$ \\
\hline
\end{tabular}

The correlation between the HA1C and (age, smoking, heart rate, family history and $\mathrm{BMI})$ in the studied sample was not significant as $(p>0.05)$. But there was a significant direct relation between HA1C and BMI (Table 2). 
Table (2): The correlation between the HA1C and age, smoking, heart rate, family history and BMI

\begin{tabular}{|c|c|}
\hline Parameters & HbA1c p value \\
\hline Age & 0.108 \\
\hline Family history & $0.0002^{*}$ \\
\hline Smoking history & 0.050 \\
\hline BMI & $<0.0001$ \\
\hline Heart rate & 0.756 \\
\hline
\end{tabular}

There were risk factors for diabetes mellitus as smoking, hypertension, obesity and dyslipidemia whish more common in both hypertension and obesity with percentage of $64.3 \%$ and $59.5 \%$ respectively (Table 3).

Table (3): Risk factors of diabetic patients in this study

\begin{tabular}{|c|c|c|c|c|}
\hline Parameters & $\begin{array}{c}\text { Cases of } \\
\text { positive }\end{array}$ & percentage & $\begin{array}{c}\text { Cases of } \\
\text { negative }\end{array}$ & percentage \\
\hline Smoking & 19 & $45.2 \%$ & $\mathbf{2 3}$ & $54.8 \%$ \\
\hline Hypertension & 15 & $35.7 \%$ & 27 & $64.3 \%$ \\
\hline Obesity & 17 & $40.5 \%$ & 25 & $59.5 \%$ \\
\hline Dyslipidemia & 22 & $52.4 \%$ & 20 & $47.6 \%$ \\
\hline
\end{tabular}

$\mathrm{HbA1c}$ and family history showed significant correlation (Figure 1).

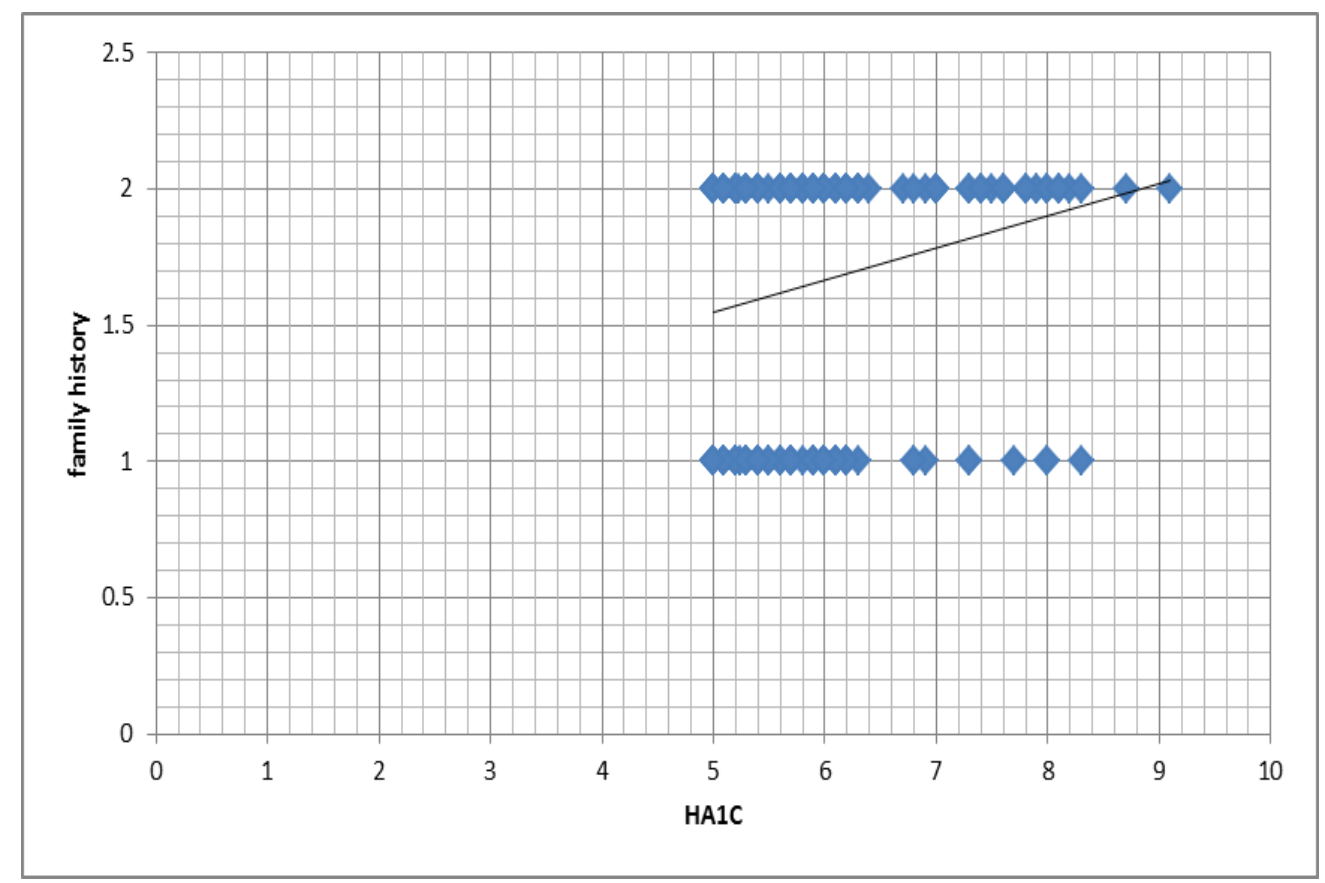

Figure (1): Correlation between the HA1C and family history.

HbA1c and BMI showed significant correlation (Figure 2). 


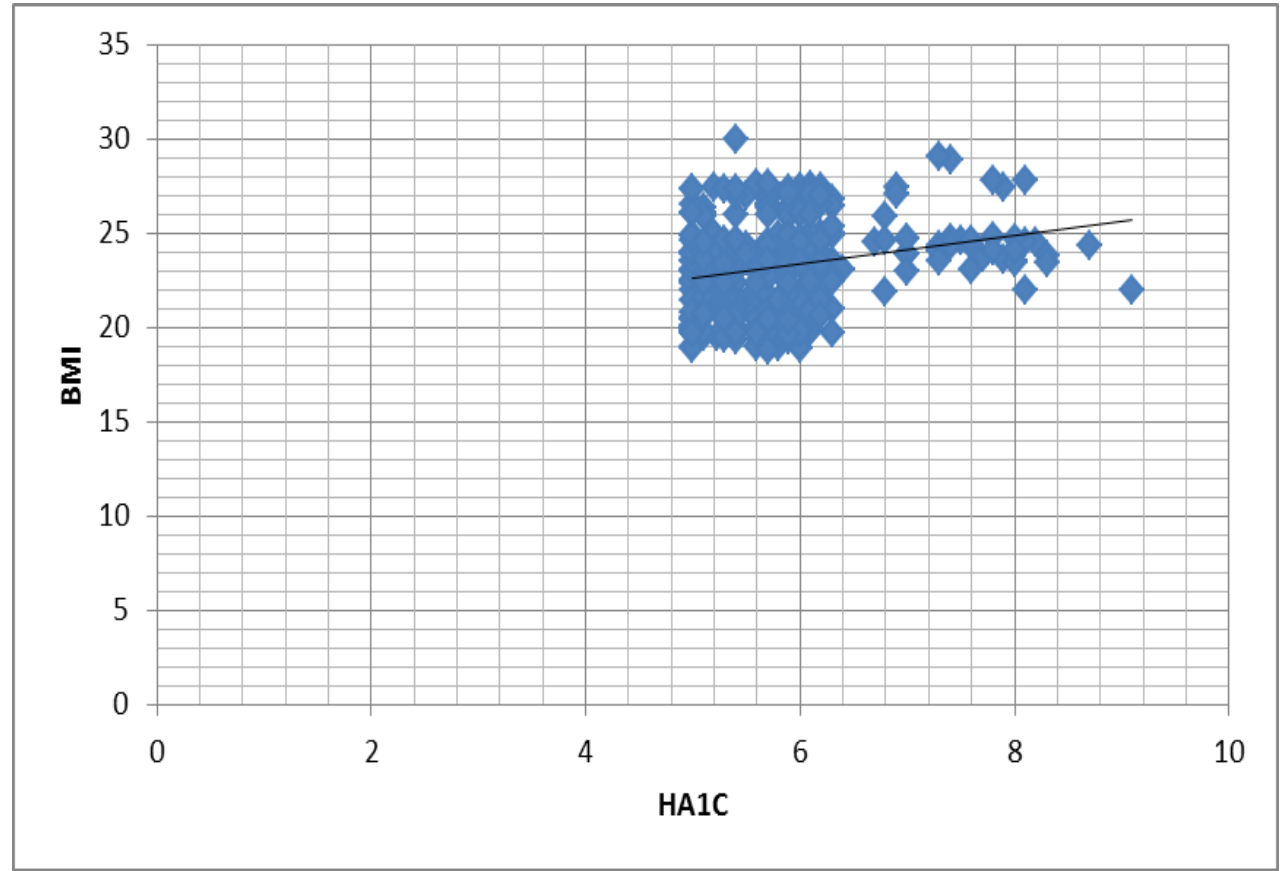

Figure (2): Correlation between the HA1C and BMI

\section{DISCUSSION}

The present study was designed to explain pre diabetic and diabetic in male students hostel of Al-Azhar University and to identify the most common risk factors. The present study included 400 male students. Their ages ranged between 18 and 24 years with a mean of 21 years. There were statistical significant correlations between HbA1c level, BMI and family history of diabetes mellitus.

According to the BMI the results of the current study revealed that were positive correlation between $\mathrm{HbA} 1 \mathrm{c}$ level and the BMI (age -weight relation).

In agreement with our study, Mokdad and Burk (2015) found that there were positive association between HbA1c level and BMI in
Diabetes mellitus and BMI was a risk factor for development DM.

$H s u$ (2015) found that $\mathrm{BMI} \geq 25$ $\mathrm{kg} / \mathrm{m}^{2}$ is a risk factor for diabetes. However, data suggest that the BMI cut point should be lower for the Asian American population.

According to family history of diabetes mellitus, the results of the current study revealed that there was a positive association between the HbA1c level and the family history of diabetes mellitus.

In agreement with our study, Meigs et al. (2011) found that there were positive association between $\mathrm{HbAlc}$ level and family history of diabetes mellitus and metabolic abnormalities of DM. Also, Tripathy et al. (2013) who found that there were positive association between HbA1c level and 
family history of diabetes mellitus and metabolic abnormalities of DM.

Hyperlipidemia is a powerful risk factor for atherosclerosis and related disorders such as ischemic heart disease, cerebrovascular diseases and retinal atherosclerosis (Gnaneswaran et al., 2013).

Smoking may increase the risk of $\mathrm{DM}$, therefore, evaluation for tobacco use and referral for tobacco cessation, if indicated, should be part of routine care for those at risk for diabetes. Of note, the years immediately following smoking cessation may represent a time of increased risk for diabetes $(\mathrm{Hu}$ et al., 2018).

The present study showed that there were no association between $\mathrm{HbA} 1 \mathrm{c}$ level, and heart rate, sex, age and smoking.

\section{CONCLUSION}

Diabetes mellitus along with its chronic complications is a serious public health concern. Individuals having pre-diabetes are becoming diabetic at a faster conversion rate. Therefore, it is extremely important to hinder, this process at an early stage.

\section{REFERENCES}

\section{Burkhauser $\mathbf{V}$ and Cawley $J$} (2008): Beyond BMI: The Value of More Accurate Measures of Fatness and Obesity in Social Science Research. Journal of Health Economic, 27(2):519-29.
2. Cunningham SA, Kramer MR and Narayan KM (2014): Incidence of childhood obesity in the United States. N Engl J Med., 370(5):403-411.

3. Ding $Y$ and Choi ME (2015): Autophagy in diabetic nephropathy. The Journal of Endocrinology, 224 (1): R15-30.

4. Giannini $C$ and Caprio $S$. (2013): Progression of $\beta$-cell dysfunction in obese youth. Curr Diab Rep., 13(1):89-95.

5. Gnaneswaran $S$, Vinodhini VM and Kuberan D. (2013): Dyslipidemia and Diabetic Retinopathy in A Rural Population, 4(3):2229-3701.

6. Gossain and Aldasouqi S. (2010): The challenge of undiagnosed prediabetes, diabetes and associated cardiovascular disease. International Journal of Diabetes Mellitus, 2(1): 43-46.

7. Hjelm, Mufunda E, Nambozi G. and Kemp J. (2013): "Preparing nurses to face the pandemic of diabetes mellitus: a literature review," Journal of Advanced Nursing, vol. 41, no. 5, pp. $424-$ 434.

8. Hsu WC, Araneta MRG, Kanaya AM, Chiang JL and Fujimoto W (2015): BMI cut points to identify at-risk Asian Americans for type 2 diabetes screening. Diabetes Care, 38:150158. 
9. Hu Y, Zong G and Liu G (2018): Smoking cessation, weight change, type 2 diabetes, and mortality. $\mathrm{N}$ Engl J Med, 379:623-632.

10. Lean ME, Leslie WS and Barnes AC. (2018): Primary care-led weight management for remission of type 2 diabetes (DiRECT): an open-label, clusterrandomised trial. Lancet 391:541-551.

11. Meigs JB, Cupples LA and Wilson PW (2011): Parental transmission of type 2 diabetes: the Framingham Offspring Study. Diabetes, 49:2201-2207.

12. Mokdad AH, Ford ES and Bowman BA (2015): Nelson DE and Engelgau MM, et al. The continuing increase of diabetes in the U.S. Diabetes Care, 24: 412416.

13. Morrison KM, $\mathrm{Xu} \quad \mathrm{L}$, Tarnopolsky M, Yusuf $Z$ and Atkinson SA (2012): Screening for dysglycemia in overweight youth presenting for weight management. Diabetes Care, 35(4):711-716.

14. Okwechime I.O. and Roberson S. (2015): Prevalence and predicators of pre-diabetes and diabetes among adults 18 years or older in florida a multinomial logistic modeling approach,'plos one, vol .10, no.12, article e0145781. Indian Journal of Endocrinology and Metabolism, 2015, Vol 37.

15. Tripathy $D$, Lindholm $E$, Isomaa B, Saloranta $C$ and Tuomi $T$ (2013): Familiarity of metabolic abnormalities is dependent on age at onset and phenotype of the type 2 diabetic proband. Am J Physiol Endocrinol Metab., 285:12971303. 


\section{معدل انتشار مرض السكر ومؤشراته بين طلبة المدينة الجامعية للأزهر بنين بالقاهرة فئرة}

محمد جميل حامد شعله1، عبدالوهاب محمد لطفي1، محمود حداد حميدة1، أحمد عزت

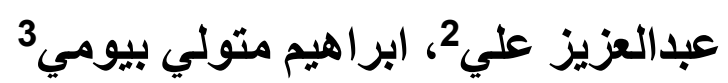
1قسم الباطنة العامة، كلية الطب البشري، جامعة الأزهر 2قسم الصحة المهنية وطب الصناعات، كلية الطب البشري، جامعة الأزهر 3قسم الباثولوجي الاكلينيكي، كلية الطب البثري، جامعة الأزهر

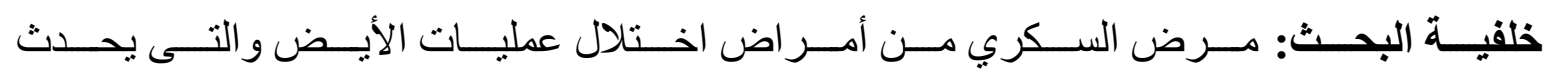

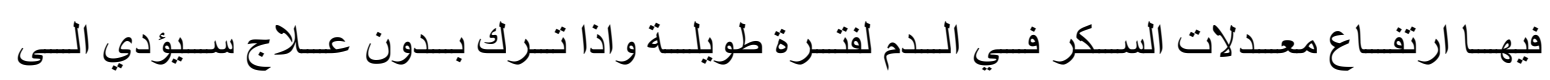
العديد من المضاعفات.

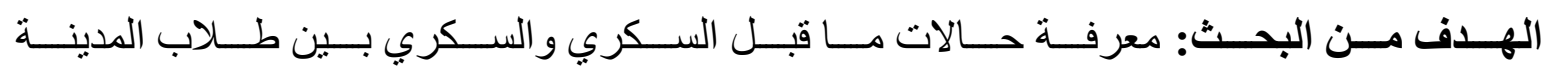
الجامعية بنين بجامعة الأز هر.

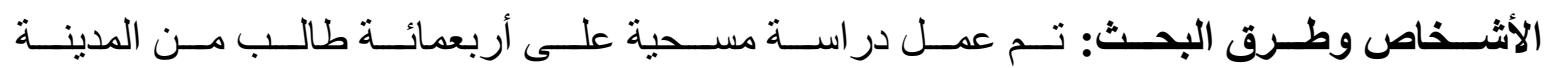

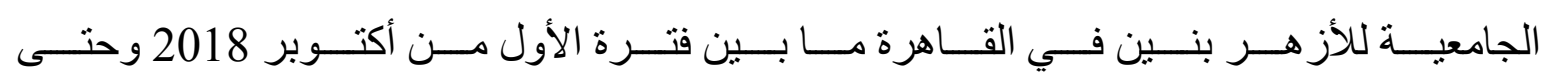
نهاية مارس 2019.

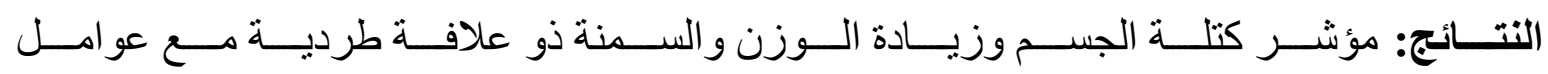

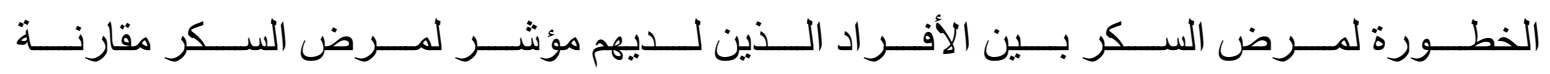
بالأشخاص الطبيعية.

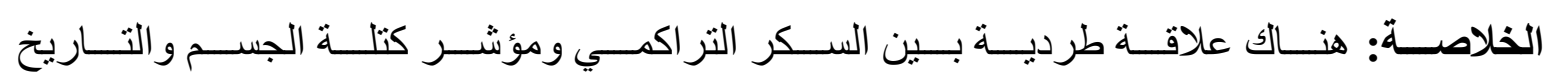
المرضي للأسرة. 